\title{
DESIGN OPTIMIZATION OF MOVEABLE MOMENT STABILIZATION SYSTEM FOR ACCESS CRANE PLATFORMS
}

\author{
Kemal Ermis $^{a, *}$, Mehmet Caliskan $^{a}$, Muammer Tanriverdi $^{b}$ \\ ${ }^{a}$ Sakarya University of Applied Science, Technology Faculty, Department of Mechanical Engineering, Esentepe \\ Campus, 54187 Serdivan-Sakarya, Turkey \\ ${ }^{b}$ Yilmaz Machine Company, IMES-5 Avenue, No: 17, 41455, Dilovası-Kocaeli, Turkey \\ * corresponding author: ermis@subu.edu.tr
}

ABstract. The popularity of aerial work platforms is rapidly increasing in the mechanization industry. As a result, the safety and structural strength of aerial work platforms should be prioritized.

In this study, the mathematical model of a reconstructed aerial work platform was developed and a 3D model was created using the Solidworks software. A dynamic analysis was then performed to improve various structural parameters of the aerial work platform. The analysis was carried out using solid modelling, finite elements, and dynamic transient analysis. In compliance with international structural standards, the weight distribution was reconstructed after placing a mass behind the turret.

The results of the dynamic transient analysis were compared with the mathematical model and validated. Then, the effect of the mass placed behind the turret on the machine was examined. The lateral tipping distance of the static work platform was found to have increased from $15.9 \mathrm{~m}$ to $17.08 \mathrm{~m}$. The structure of the aerial work platform was improved using a structural and dynamic analysis approach. It was also discovered that the machine efficiency could be further increased by ensuring that the balancing weight is moved further away from the tower centre by a hydraulic-based system and controller.

KEYwORDs: Dynamic analysis, structural analysis, mechanic, aerial work platform.

\section{INTRODUCTION}

Nowadays, aerial work platforms are designed to provide people with a means to reach heights not feasible otherwise and are rapidly rising in popularity in the mechanization sector [1, 2]. Previously, this task was carried out using attachments placed on mobile cranes [3]. However, following the ban of this practice, the use of aerial work platforms has become mandatory and has led to the increased production of aerial work platform machines [4. Initially, aerial work platforms were put into production to replace scissor lifts, previously used to reach fruit trees when the users of these lifts needed a higher reach. Due to the use of aerial work platforms becoming more widespread, the areas of use have also expanded. Nowadays, aerial work platforms are found in various industrial sectors and are being used to carry out jobs such as cleaning the exterior surfaces of high-rise buildings, the assembly of roof systems, connecting electric poles, surface treatments in shipyards, and firefighting operations 2. Some variations in the construction of aerial work platforms include articulated, scissor lift, and telescopic platforms [5]7].

These aerial work platforms have become increasingly popular in the mechanization sector, which means that these machines must provide the desired elevation required by the consumers' height demands, but the cost of these machines must remain competitive in narrow market conditions. There are many producers of small and medium-sized aerial work platforms around the world. However, with the expansion of the international market, the pressure on the producers of aerial work platforms has increased rapidly.

\section{The General STRUCTURE OF AERIAL WORK PlatFormS}

Aerial work platforms generally consist of a carrier vehicle, chassis, turret, booms, and basket sections [8, 9]. Nowadays, when manufacturing aerial work platforms, the goal is to reach a vertical height of 26 meters, as shown in Figure 1

A damage to aerial work platforms mainly results from pushing the machine to extend past its limits along the horizontal axis [10. When users first select the machine they need, they consider the total working height capacity, the lateral extension limit, and the total weight [11, 12. The two parameters that limit the capacity of the lateral extensions of the machine affect the stability of the outrigger tipping points and act as counterweights are the platform chassis and the mass of the turret [10, 13].

The total weight of the aerial work platform produced determines the specification of the vehicle under it [14, 15]. The limitations in the carrying capacity of the carrier vehicles as well as the total cost of these 


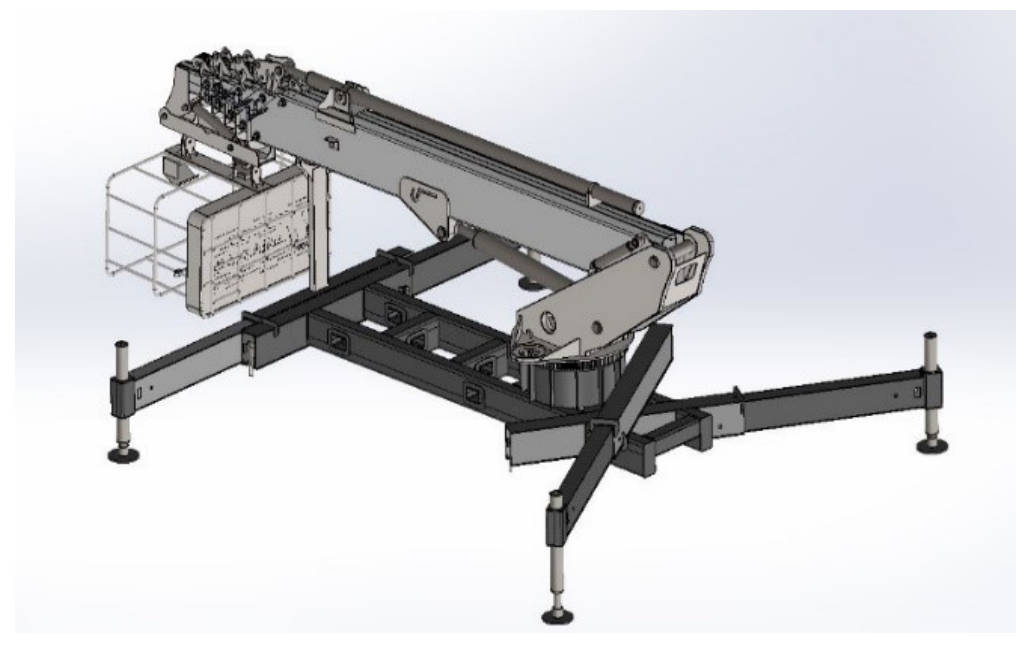

Figure 1. A typical telescopic aerial work platform that has a 26-meter extension.

machines affect the users of these vehicles. Increasing the weight capacity and the cost of the carrier vehicle leads to an increase in the travel costs of these aerial work platforms, which are used as mobile vehicles. In general, the design of the machine determines the cost and users select these carrier vehicles based on their design.

In the aerial work platform manufacturing industry, manufacturers often avoid compromising safety [1. They are especially reluctant when it comes to making changes to the boom structure. However, with the machinability of high-strength steel sheets, and the increased bending ability and level of the brittleness of high yield strength hard materials, it is possible to produce low weight booms and thus more effective machines [7, 16. It is obvious that there should not be any restrictions placed on the improvement and development of each of the elements that constitute these machines, and that this should be an important factor considered by internationally prominent manufacturers.

In addition, the structural strengths of the machines have been examined in international studies [4, 17, 18, and in the case of one of these studies, improvements were made for HT26 [5]. In some studies, structural improvements have been achieved by examining the effects of bearing loads obtained directly by using dynamic modelling on the machines [11].

In this study, building on previous studies and experiments [19, 20, improvements will be made through realistic systems constructed using advanced multi-body dynamic system modelling (MSc Adams ${ }^{\circledR}$ ). All standards, except for the wind and hand forces will be applied according to EN280 [8] regulations. All the behaviours of the constructed structure will be examined. In this study, the working capacity of aerial work platforms, improvements to their working capacity, and suggestions for how these improvements could be further amplified are examined in detail.

\section{WORK METHOD}

The work method consists of; the outrigger contact force function formula with physical properties, the improvement of the aerial work platform structure, the development of the mathematical model of the aerial work platform, and the process of structural and dynamic structural analysis.

The methodology of this study is shown in Figure 2

The 3D modelling for the aerial work platform was performed using the Solidworks software based on the mathematical model results for the initial and boundary conditions of geometry. Then, the completed model was exported to a Parasolid file. The CAD data were then used to prepare the mesh structure using the Msc Apex Software, and then a Nastran document file was created to be used for the finite element analysis. In the finite element analysis section, defined starting and boundary conditions were applied in the MSc Simxpert software, and then a model analysis was performed to create a data file that was used for the dynamic transient analysis performed using the MSc Adams software. Results of the finite element analysis were compared with the theoretical maximum stress and deflection.

\subsection{OUtRIGGER CONTACT FORCE FUNCTION FORMULA}

The impact function has seven variables, which all correspond to properties of the physical world.

$$
\operatorname{IMPACT}\left(x, \dot{x}, x_{1}, k, e, c_{\max }, d\right)
$$




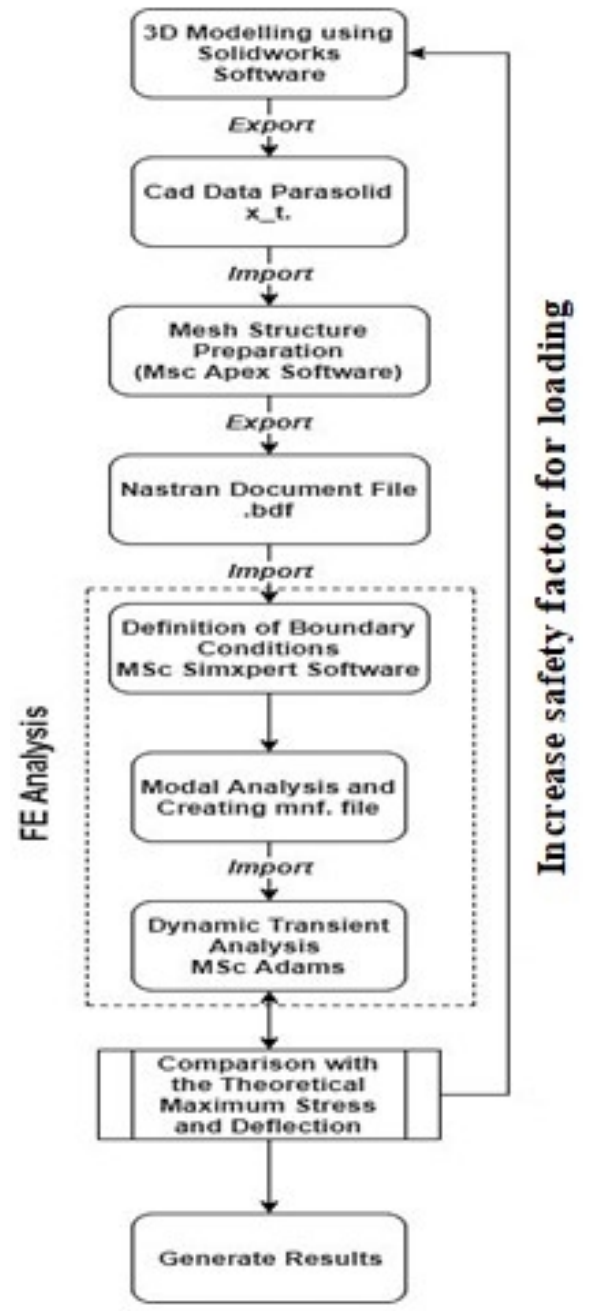

Figure 2. Flow chart of this study.

$k=$ Stiffness " $10 \mathrm{E}+8 \mathrm{~N} / \mathrm{m}$ "

$e=$ Force exponent " 2.2 - Steel"

$c=$ Max damping " $10 \mathrm{E}+4 \mathrm{~N} \cdot \mathrm{s} / \mathrm{m}$ "

$d=$ Penetration depth "10E-2 mm"

$$
f=\left\{\begin{array}{cc}
0 & \text { if } x>x_{1} \\
k\left(x_{1}-x\right)^{e}-c_{m a x} \dot{x}\left(\operatorname{STEP}\left(x,\left(x_{1}-d\right), 1, x_{1}, 0\right)\right) & \text { if } x \leq x_{1}
\end{array}\right\}
$$

The assumptions taken into account in the dynamic analysis process are as follows.

- All construction elements consist of rigid elements.

- The effect of the wind load on the basket platform is not taken into account.

- The machine is able to move at a certain DOF by defining a "spherical joint" on the foot shoes of the platform with the basket towards the tipping direction.

- The chains on the machine booms are eliminated and the motion equations that will model these chains are applied to the booms and the operation of the machine is modelled.

- A gravitational acceleration of $9.81 \mathrm{~m}^{2} / \mathrm{s}$ is applied on the structure vertically on the Y-axis.

\subsection{IMPROVEMENT OF AERIAL WORK PLATFORM STRUCTURE}

The aim of this study is to increase the working efficiency of aerial work platforms a through lateral extension. Figure 3 shows the lateral extension of the 26-meter platform. As the axis of the tipping moment, the contact points of the vertical outrigger are illustrated on the figures and the working limits of the machine can be determined by calculating the moment based on the $250 \mathrm{~kg}$ load. The weights of the platform components based 


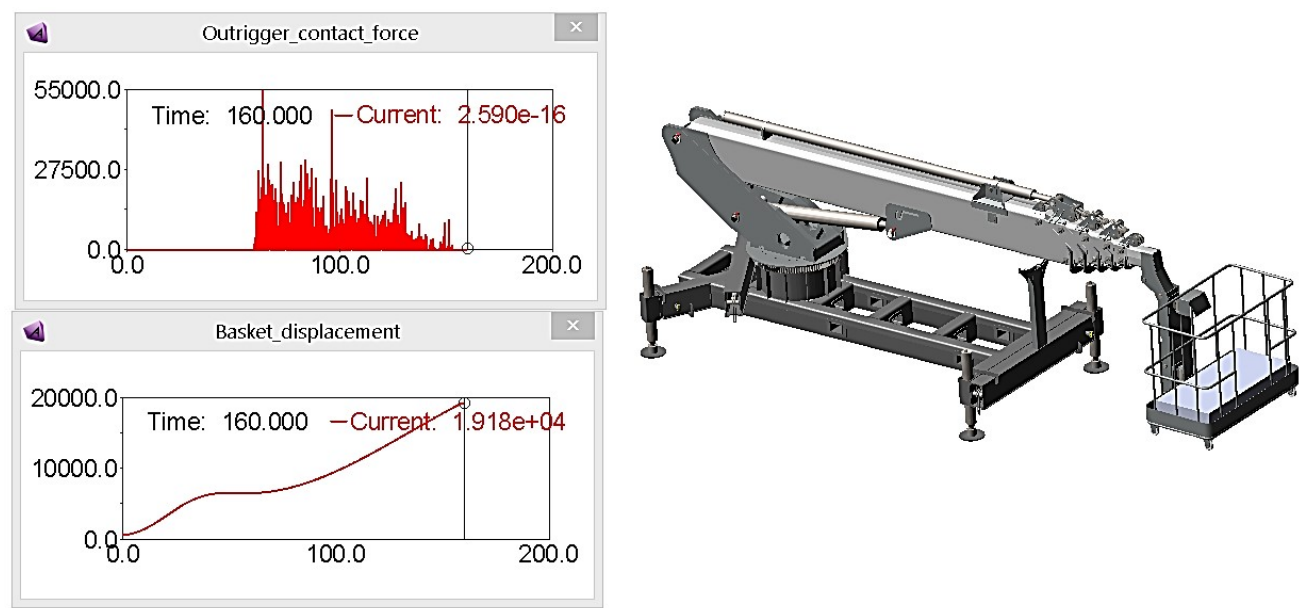

Figure 3. Statically calculated lateral working capacity of Aerial Work Platform by MSc Adams ${ }^{\circledR}$.

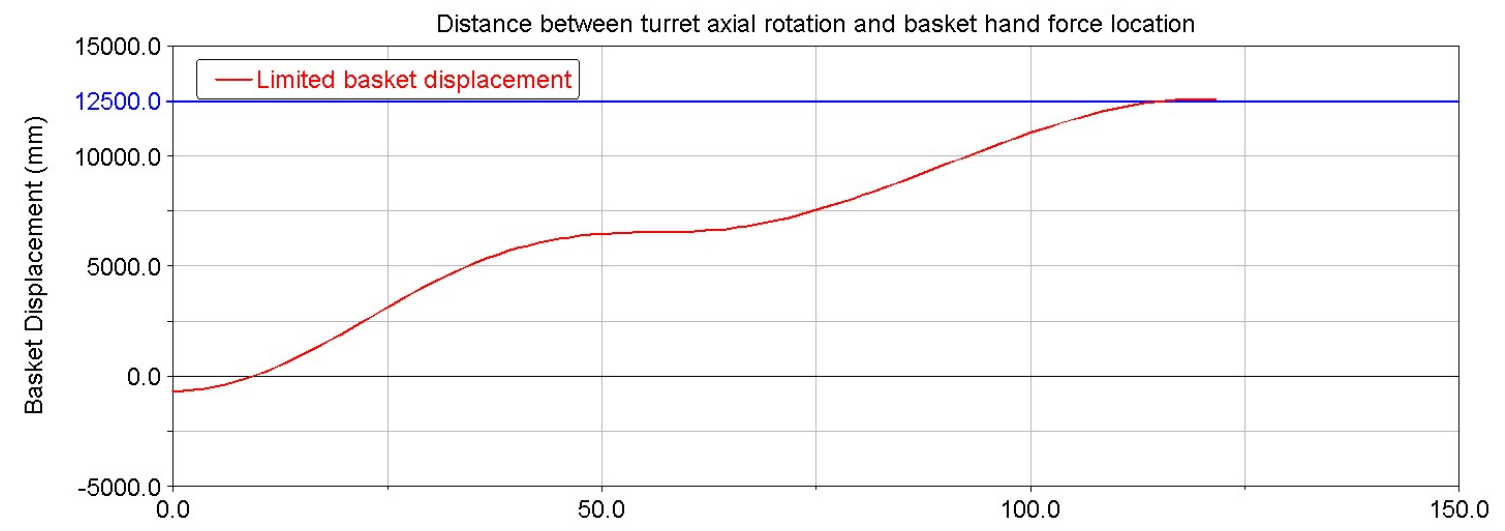

Figure 4. Statically limited working displacement of Aerial Work Platform lateral extension by MSc Adams ${ }^{\circledR}$.

on the moment arm distances given in Figure 3 as follows: Basket and load $(250+120 \mathrm{~kg})$, booms $(1380 \mathrm{~kg})$, turret $(430 \mathrm{~kg})$, machine chassis $(1120 \mathrm{~kg})$, and vehicle mass $(2830 \mathrm{~kg})$.

In a conventional design process, the determination of the tipping moment and the working diagram of the machine were made based on basic static calculations. According to these static loads, the construction tipping limit was calculated to be $19.1 \mathrm{~m}$. $\left(\mathrm{MSc}\right.$ Adams ${ }^{\circledR}$ ) (Fig. 3). However, these limits are a result of the structural analysis previously carried out on the booms where the safety factor was limited to a maximum of 2 and it could be extended up to 15 meters. Based on this limit value, a safety coefficient of 1.2 was used so the structure could statically remain under control. After the production, the limitations on lateral extension are electronically generated by controlling the pistons as shown in Figure 4

\subsection{MATHEMATICAL MODEL OF AERIAL WORK PLATFORM}

The mathematical model of the aerial work platform was used to define the initial and boundary conditions for the numerical analysis. Also, the mathematical model results provide limit values for the numerical analysis. These limits are important in ensuring the safety and control for every step of the numerical analysis. The extendable boom's free body diagram is shown in Figure 5 .

In figure 5. where $L_{1}$ is the extendable boom length, $L_{2}$ is the length of basket arm, $\theta$ angle between the boom and the horizontal $l, m_{1}$ is the total mass of booms, $m_{2}$ is mass of basket arm, $m_{3}$ is the load in the basket, $I_{1}$ is the mass moment of inertia on the main boom and $I_{2}$ is the mass moment of inertia on the basket arm. (Fig. 5). Instead of forces, the Lagrangian mechanics $(L)$ use the energies that can be described by the difference between kinetic energy $(K E)$ and potential energy $(P E)$ as shown in equation 3

$$
L=K E-P E
$$

The non-relativistic Lagrangian for a system of particles can be defined by

$$
L=T-V
$$

where $T$ is the total kinetic energy of the system's motion and $V$ is the potential energy of the system. 


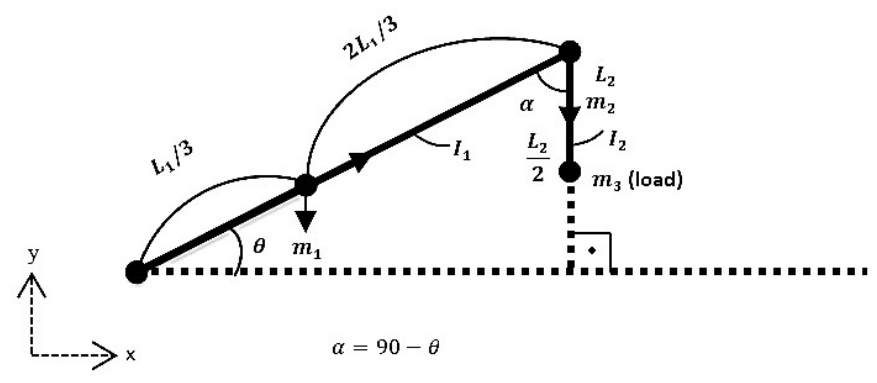

Figure 5. Free body diagram.

The kinetic energy depends on time. Using generalized Coordinates $\left(\theta, L_{1}\right)$, following equations can be derived.

$$
\begin{gathered}
\frac{d}{d t}\left(\frac{\partial T}{\partial \dot{\theta}}\right)-\frac{\partial V}{\partial \theta}=m_{3} g \\
\frac{d}{d t}\left(\frac{\partial T}{\partial \dot{L_{1}}}\right)-\frac{\partial V}{\partial L_{1}}=m_{3} g
\end{gathered}
$$

Coordinates can be calculated as follows:

$$
\begin{aligned}
& x=L_{1} \cos (\theta) \\
& y=L_{1} \sin (\theta)
\end{aligned}
$$

The kinetic energy of the system is given as follows

$$
T=\left\{\frac{1}{2} m_{1}\left(\dot{x}^{2}+\dot{y}^{2}\right)+\frac{1}{2} I_{1} \dot{\theta}^{2}+\frac{1}{2} m_{1}{\dot{L_{1}}}^{2}+\frac{1}{2} m_{2} \dot{y}^{2}+\frac{1}{2} m_{3} \dot{y}^{2}+\frac{1}{2} I_{2} \dot{y}^{2}\right\}
$$

The potential energy of the system is given as follows

$$
\begin{gathered}
V=\left\{m_{1} g \frac{L_{1}}{3} \sin (\theta)+m_{2} g\left(L_{1} \sin (\theta)-L_{2}\right)+m_{3} g\left(L_{1} \sin (\theta)-L_{2}\right)\right\} \\
T-V=m_{3} g
\end{gathered}
$$

For " $\theta$ ";

$$
\begin{gathered}
\frac{d}{d t}\left(\frac{\partial T}{\partial \dot{\theta}}\right)-\frac{\partial V}{\partial \theta}=m_{3} g \\
\left\{I_{1} \ddot{\theta}-\left(m_{1} g \frac{L_{1}}{3}\right) \cos (\theta)+m_{2} g L_{1} \cos (\theta)+m_{3} g \sin (\theta)\right\}=m_{3} g
\end{gathered}
$$

For " $L_{1}$ ";

$$
\begin{gathered}
\frac{d}{d t}\left(\frac{\partial T}{\partial \dot{L_{1}}}\right)-\frac{\partial V}{\partial L_{1}}=m_{3} g \\
\left\{m_{1} \ddot{L}_{1}-\left(m_{1} g \sin (\theta)+m_{2} g \sin (\theta)+m_{3} g \sin (\theta)\right)\right\}=m_{3} g
\end{gathered}
$$

Using the above equations, the following equations are found

$$
\begin{gathered}
I_{1} \ddot{\theta}-g \cos (\theta)\left\{\frac{L_{1}}{3} m_{1}+m_{2} L_{2}+m_{3} L_{1}\right\}=m_{3} g \\
m_{1} \ddot{L_{1}}-g \sin (\theta)\left\{\frac{1}{3} m_{1}-m_{2}-m_{3}\right\}=m_{3} g
\end{gathered}
$$




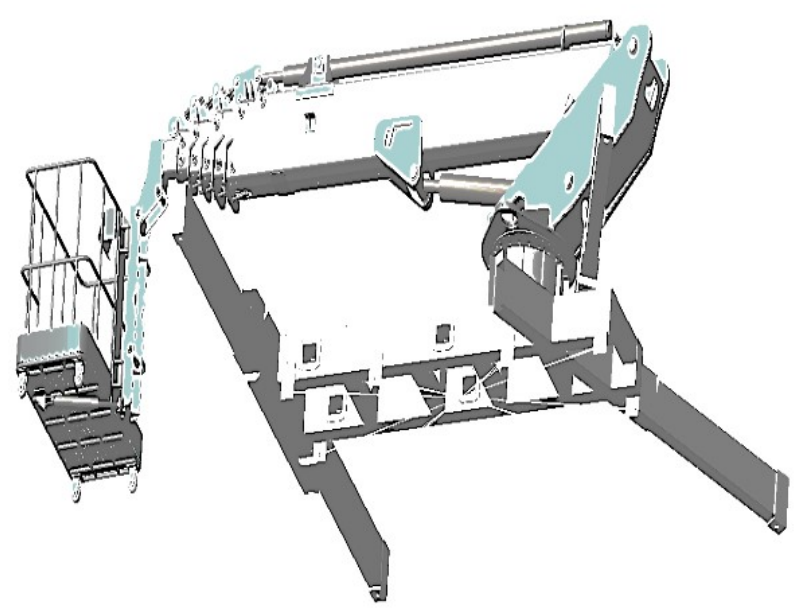

Figure 6. Definition of vehicle weight by point mass using RBE2 rigid connectors (MSC Adams ${ }^{\circledR}$ ).

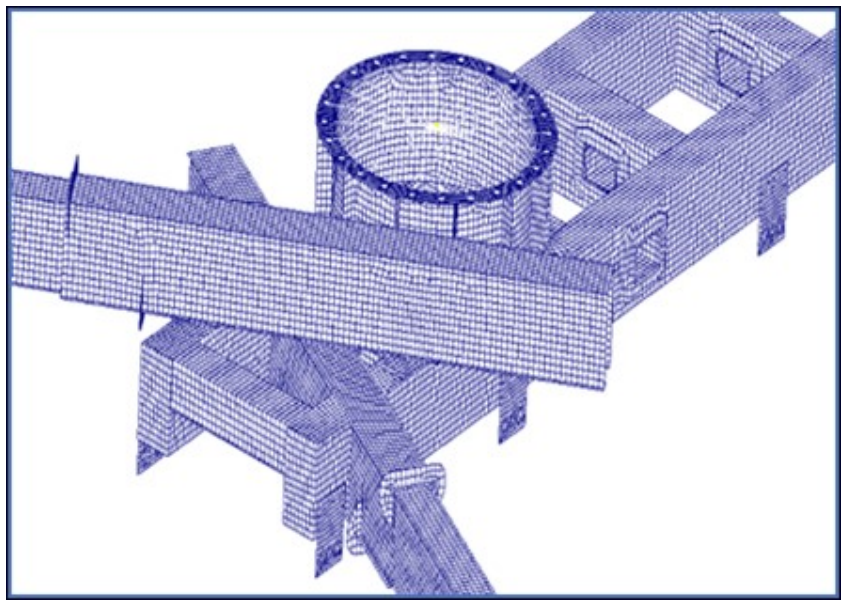

Figure 7. The mesh design of chassis structure with 2D elements created by using MSc Apex ${ }^{\circledR}$.

\subsection{The Process of STRUCtURAL AND DyNAMiC STRUCTURAl ANALYSiS}

The MSC Adams ${ }^{\circledR}$ multi-body dynamic system modelling program was used to construct the structure. In this dynamic model, the structure has been created with rigid connectors, Instead of the balancing piston, which allows the basket to run parallel to the ground plane during the machine operation, the primitive joint was attached onto the basket, thus allowing the basket to always move perpendicular to the ground plane. The lateral working capacity of the aerial work platform was calculated using the model prepared in the MSC Adams dynamic system modelling program (Fig. 3).

In accordance with the method applied, the lateral working capacity of the aerial work platform was calculated to be 19.1 meters. As shown in Figure 3, the outrigger contact force was determined to be zero at the time of $160 \mathrm{~s}$. If the analysis were to be continued at this point, this outrigger contact force value would remain negative and this would suggest that it is not in contact with the ground. The value observed on the graph at the $160 \mathrm{~s}$ mark is $1.918 \mathrm{E}+4 \mathrm{~mm}$. This value is equal to $19180 \mathrm{~mm}$ which can also be expressed as $19.1 \mathrm{~m}$. During the machine manufacturing process, this value is divided by a safety coefficient of 1.2 as a more reliable static working capacity is preferred. The final lateral working capacity was consequently determined to be 15.9 meters. During the creation of the dynamic model, a $250 \mathrm{~kg}$ basket load and a $2780 \mathrm{~kg}$ vehicle load were applied to the model. The vehicle load was placed onto the vehicle's centre of gravity, which is defined as the centre of mass based on the connection point between the machine and the vehicle, and it was connected to the structure with an appropriate connection element (spherical joint) as shown in Figure 6

Chassis-vehicle connection plates were modelled to be welded on the machine chassis before proceeding to the structural analysis process so that the prepared mesh elements could be used in MSC Adams ${ }^{\circledR}$ as shown in Figure 7 


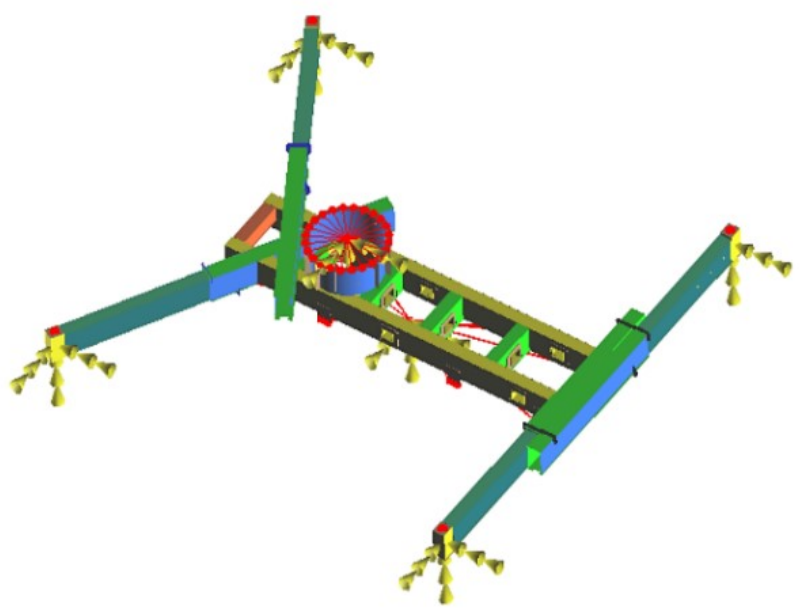

Figure 8. Creation of ASET locations on flexible model using MSc Simxpert ${ }^{\circledR}$.

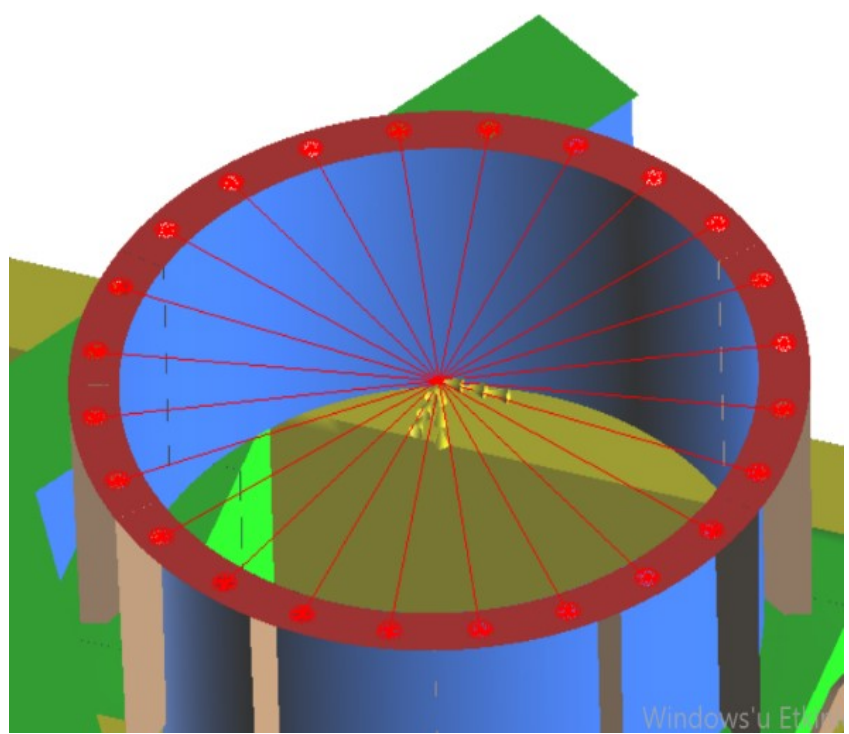

Figure 9. Definition of ASET, which provides transfer of forces between rigid and flexible parts created by using MSc Simxpert ${ }^{\circledR}$.

The results showed that the maximum lateral extension distance of the machine under rigid conditions was 15.9 meters. As further improvements are made to the structure of the machine, it is assumed that the booms are composed of rigid elements.

However, the effect of this distance on the vehicle chassis varies according to the behaviour of the material and structure used. The elements of the machine chassis are composed of sheet metal elements. Using the mid-surface feature, 2-dimensional elements were formed. The MSc Apex ${ }^{\circledR}$ commercial software was used to model the entire structure in detail during the FEM geometry creation phase. Welded regions were rearranged by creating new mesh elements.

The process of creating an MNF document after the modal analysis includes the preparation of load transfer nodes on the MSC Simxpert ${ }^{\circledR}$ software (ASET), creating a new connector node suitable for these nodes, creating a new connector node suitable for these nodes, and material definition as shown in Figure 8

"Structural steel" is defined as the material used for the construction of the structure and the St52 steel parameter was taken into consideration as yield strength (353 MPa), as shown in Figure 9 .

Structural Steel specifications: Young's Modulus: $210000 \mathrm{MPa}$, Poisson's Ratio: 0.3, and Density: 7.85E$6 \mathrm{~kg} / \mathrm{mm}^{3}$.

The obtained flexible chassis model was applied on a previously prepared dynamic model. The chassis model, which had been previously solved dynamically, was solved again with the flexible chassis structure. The 


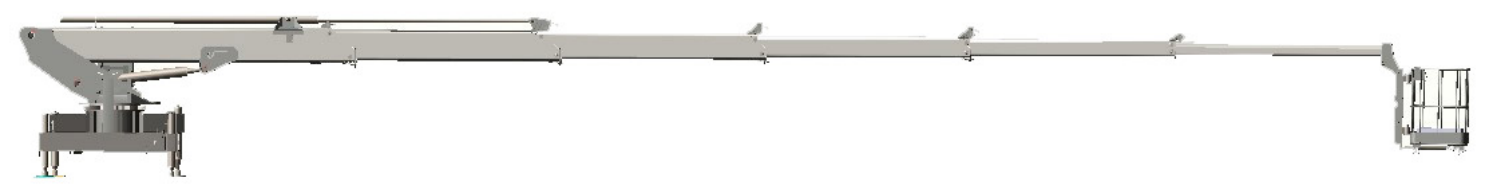

FiguRE 10. Rigid dynamic model of aerial work platform created using MSc Adams ${ }^{\circledR}$.

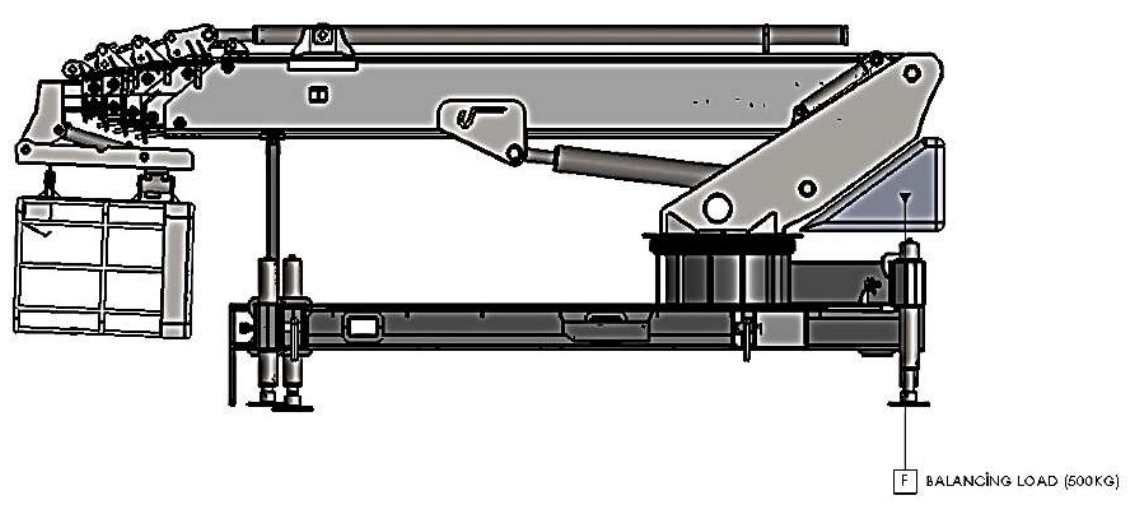

Figure 11. Definition of ASET which provides transfer of forces between rigid and flexible parts created by using MSc Simxpert ${ }^{\circledR}$.

lateral working limit of the machine was calculated by considering the yield strength and the safety factor of the material used as shown in Figure 10.

As another parameter, the effect that the balance weight $(500 \mathrm{~kg})$, which was placed behind the turret on the machine to increase its lateral extension, had on the working efficiency of the machine was examined. The balancing weight, defined as a point mass, was placed $1125 \mathrm{~mm}$ away from the centre of the turret so that it did not interfere with the rotation of the machine behind the turret. The balancing weight was positioned at the minimum distance away from the centre of the turret after taking the volume to be covered with steel (which has a weight of $500 \mathrm{~kg}$ and has a density of $7.85 \mathrm{~g} / \mathrm{cm}^{3}$ ) into consideration as shown in Figure 11

In this model, which is constructed using dynamic structural modelling, the working limit of the machine has been determined by taking the chassis strength, material used, and the safety coefficient into consideration as shown in Figure 12 In the model, the weight of the vehicle is defined as a point mass with all the structure weights and inertial behaviours. Welded connection plates are used on the chassis for the distribution of vehicle weight as well as for more realistic load distributions. These connections are assembled around a single node with RBE2 elements (Fig. 7). The effect of the balancer weight, placed behind the turret, on the working efficiency of the machine is observed for the sample as shown in Figure 13.

Using a $500 \mathrm{~kg}$ load as a balancer weight placed behind the turret and positioning this load $1125 \mathrm{~mm}$ away from the centre of the turret increased the aerial work platform's lateral working capacity to 20.5 meters.

\section{Results AND Discussion}

As a result of this analysis and other working scenarios, on the machine chassis, low load distributions were observed in the section extending to the rear outriggers. It was determined that the machine work efficiency could be increased by distributing this load to the whole machine and moving the centre of gravity closer to the turret rotation centre.

As a result, the lateral working capacity of the statically improved aerial work platform was determined to be 17.08 meters when a safety factor coefficient of 1.2 was used in the calculations.

The effects of elongation and shortening of the boom of the crane were analysed. The contact force graph was created to determine the lateral tipping limit of the vehicle in line with the data obtained from the dynamic model as shown in Figure 14. According to the results, the lateral distance between the tip of the machine basket to the tower-boom rotation axis was determined to be approximately 18.5 meters. However, this distance was further limited by approximately 0.3 percent, providing a safer operation and better structural protection of the machine. 


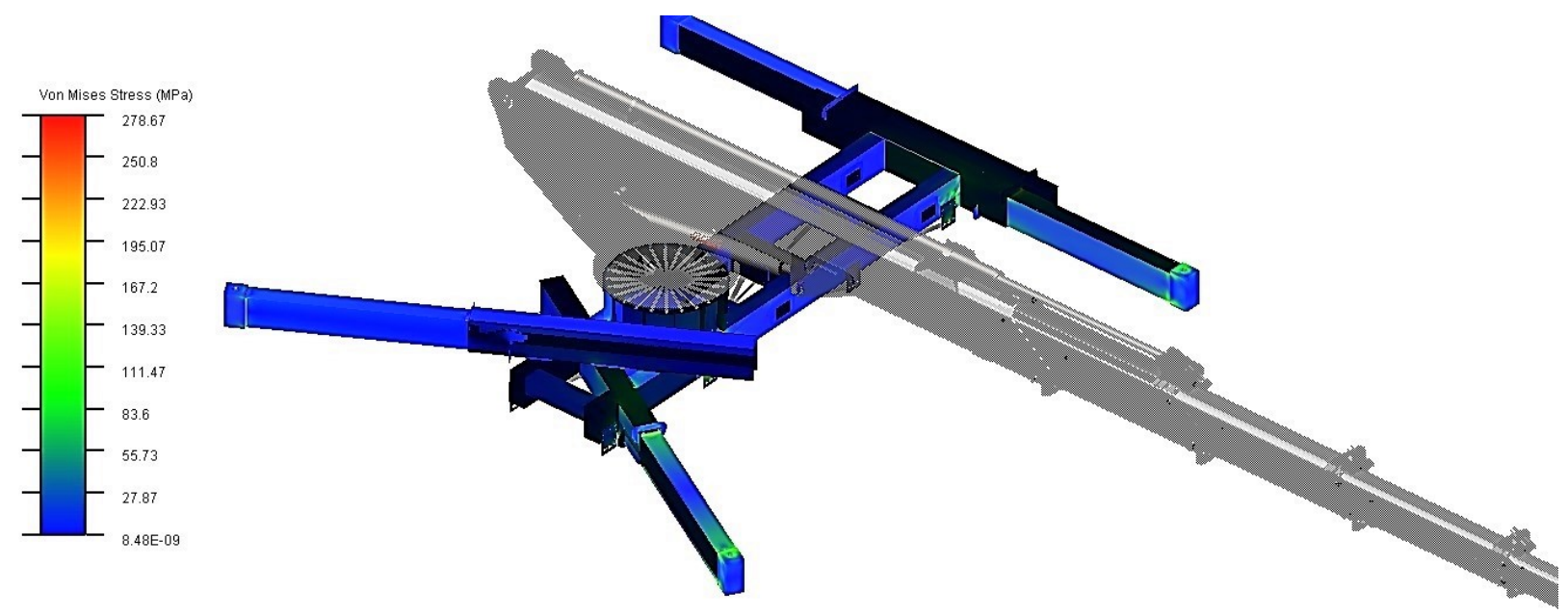

FigurE 12. The structural effect of the lateral extension of the platform on the chassis (MSc Adams).

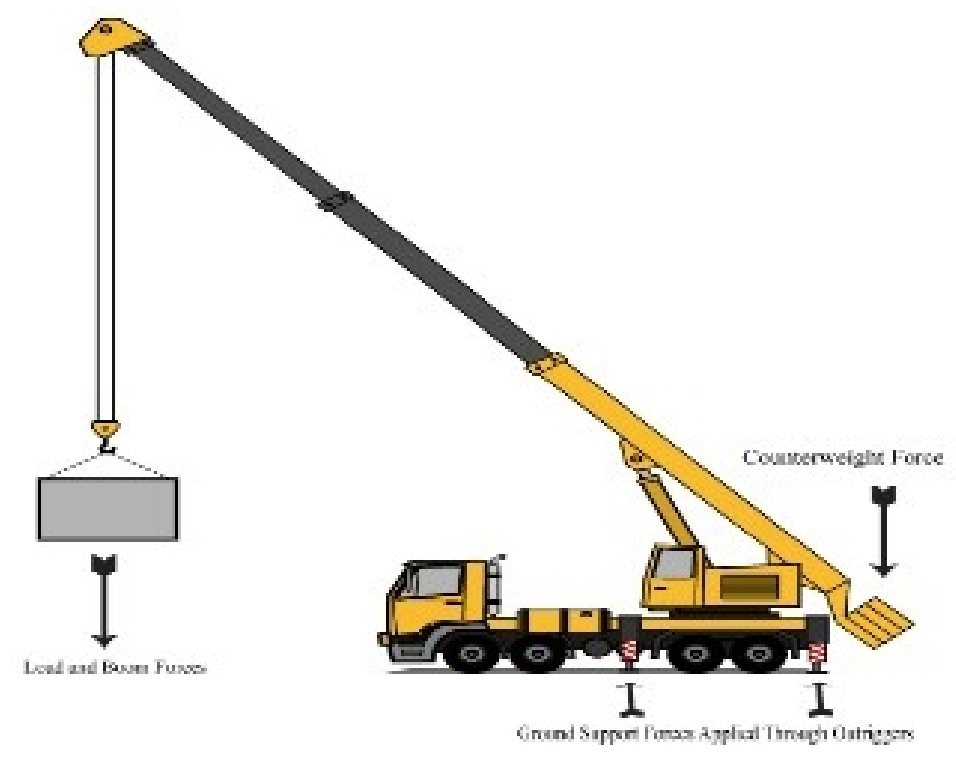

FigURE 13. Sectorial application of balancing weight.

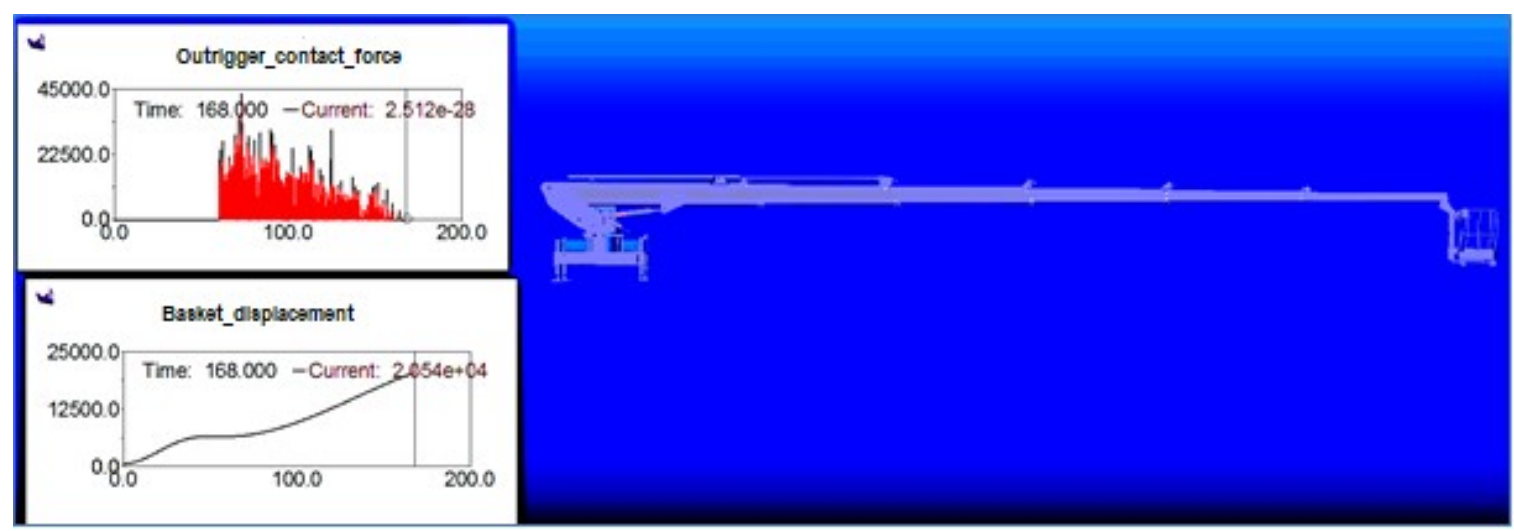

FIGURE 14. Lateral (elongation) overturning moment calculation. 


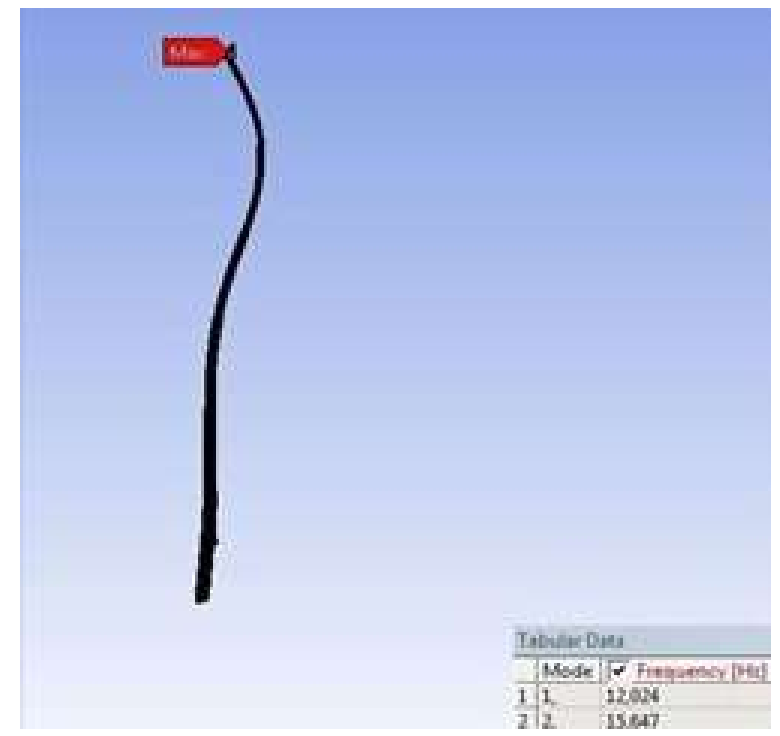

Figure 15. Mode Shape of the booms on $12 \mathrm{~Hz}$ frequency.

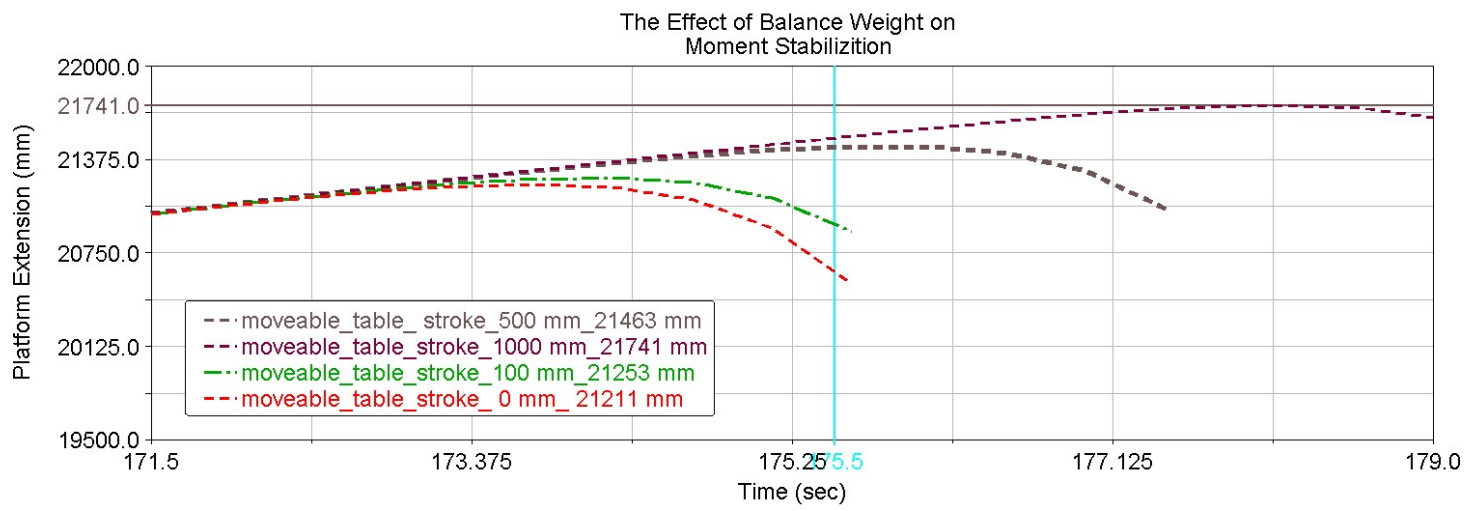

Figure 16. The effect of hydraulic table stroke distance on boom extension.

With the results obtained, the maximum lateral extension distance of the machine under rigid conditions was determined to be 18.5 meters. The effect of a counterbalance weight $(500 \mathrm{~kg})$ behind the tower, which can be used to increase the machine lateral extension distance efficiency, on the machine work efficiency has been investigated. The effect of the tower back balancer weight on the machine side work efficiency is observed in Figure 14

Accordingly, the machine shows a greater tipping limit distance, which is 20.5 meters, thanks to the $500 \mathrm{~kg}$ load used as a balancing weight. According to this result, with a safety ratio of 0.3 , the side working capacity of the machine can be increased up to 15 meters.

This value of the lateral working capacity was obtained when the balancer weight placed behind the tower was stationary. This value can be increased by using a movable hydraulic table, which can be placed on the balancing weight base. The effect of the $1000 \mathrm{~mm}$ hydraulic moving table stroke on the platform lateral capacity can be seen in Figure 15

The natural frequencies of booms are critical in generating resonances, which can damage the machine. The truck was placed under the aerial work platform and ran approximately at idle speed. This idle speed range is between 700 to $1000 \mathrm{rpm}$.

The effect of the balancing weight on the displacement of the boom extension with the use of the movable table is observed in Figure 16. The use of a counterweight on the back of the turret helps to improve the rigidity of the turret.

When the working platform is at the top, the dynamic load will affect the turret more aggressively.

Therefore, along with structural improvements and weight optimizations that can be made on aerial work platforms, balancing weights can also be used to optimize results.

From the results obtained using the flow diagram seen in Figure 16 , the distance of the aerial work platform lateral tipping distance, statically calculated to be 15.9 meters, was extended to reach up to 17.08 meters. It was observed that the machine efficiency could be further increased by ensuring that the balancing weight is 
moved further away from the tower centre by a hydraulic-based system and controller. (The structure of the boom has been considered rigid). From these results, the effect of weight optimization of the machine chassis, tower, elevation box, and outriggers by means of weight and structure improvements of the machine have been determined. By taking these results into consideration, it will be possible to provide more secure and more efficient operation of aerial work platforms that are used to complete many tasks. Future studies can examine the aerodynamic effects of different air velocities and directions on aerial work platforms.

\section{ACKNOWLEDGEMENTS}

The authors wish to thank Bias Engineering for their substantial help with the dynamic system modelling.

\section{REFERENCES}

[1] H. Hu, E. Li, X. Zhao, et al. Modeling and simulation of folding-boom aerial platform vehicle based on the flexible multi-body dynamics. In International Conference on Intelligent Control and Information Processing, pp. 798 - 802. IEEE, Dalian, China, 2010. DOI:10.1109/ICICIP.2010.5565257

[2] M. Sezer, M. Kalyoncu. Cage levelling control of truck-mounted hydraulic aerial work platforms. Selcuk University Journal of Engineering, Science and Technology 2(2):1 - 9, 2014. DOI:10.15317/scitech.201426889.

[3] R. G. Dong, C. S. Pan, J. J. Hartsell, et al. An investigation on the dynamic stability of scissor lift. Open Journal of Safety Science and Technology 2(01):8 - 15, 2012. DOI:10.4236/ojsst.2012.21002.

[4] A. Yucel, A. Arpaci. Analytical and experimental vibration analysis of telescopic platforms. Journal of Theoretical and applied Mechanics 54(1):41 - 52, 2015. DOI:10.15632/jtam-pl.54.1.41.

[5] M. Karahan. Design and finite element analysis of two levels telescopic crane. Master's thesis, Atatürk University, Erzurum, Turkey, 2007.

[6] H. Marjamäki, J. Mäkinen. Modelling a telescopic boom - the 3D case: Part II. Computers 83 structures 84(29 30):2001 - 2015, 2006. DOI:10.1016/j.compstruc.2006.08.010

[7] A. Trabka. Dynamics of telescopic cranes with flexible structural components. International Journal of Mechanical Sciences 88(29):162 - 174, 2014. DOI:10.1016/j.ijmecsci.2014.07.009.

[8] CEN - EN 80 - Mobile elevating work platforms - Design calculations - Stability criteria - Construction - Safety Examinations and tests. Standard, European Committee for Standardization, 2013.

[9] M. A. M. Nor, H. Rashid, W. M. F. W. Mahyuddin, et al. Stress analysis of a low loader chassis. Procedia Engineering 41:995 - 1001, 2012. DOI:10.1016/j.proeng.2012.07.274.

[10] S. M. Bošnjak, N. B. Gnjatović, D. B. Momčilović, et al. Failure analysis of the mobile elevating work platform. Case Studies in Engineering Failure Analysis 3:80 - 87, 2015. DOI:10.1016/j.csefa.2015.03.005.

[11] J. Guo, H. He, C. Sun. Analysis of the performance of aerial work platform working device based on virtual prototype and finite element method. Energy Procedia 104:568 - 573, 2016. DOI:10.1016/j.egypro.2016.12.096.

[12] E. Maleki, B. Pridgen, J. Q. Xiong, W. Singhose. Dynamic analysis and control of a portable cherrypicker. In ASME 2010 Dynamic Systems and Control Conference, pp. 477 - 482. 2010. DOI:10.1115/DSCC2010-4241.

[13] S. He, M. Ouyang, J. Gong, G. Liu. Mechanical simulation and installation position optimisation of a lifting cylinder of a scissors aerial work platform. The Journal of Engineering 2019(13):74 - 78, 2019. DOI:10.1049/joe.2018.8961

[14] L. Shanzeng, Z. Lianjie. Kinematics and force analysis of lifting mechanism of detachable container garbage truck. The Open Mechanical Engineering Journal 8(1):219 - 233, 2014. DOI:10.2174/1874155X01408010219.

[15] T. Erdol. Design, analysis of the gantry crane with finite element method and box girder optimization. Master's thesis, Gebze Institute of Technology, Gebze, Turkey, 2007.

[16] B. Posiadala, D. Cekus. Discrete model of vibration of truck crane telescopic boom with consideration of the hydraulic cylinder of crane radius change in the rotary plane. Automation in Construction 17(3):245 - 250, 2008. DOI:10.1016/j.autcon.2007.05.004.

[17] F. Yao, W. Meng, J. Zhao, et al. Analytical method comparison on critical force of the stepped column model of telescopic crane. Advances in Mechanical Engineering 10(10):1 - 13, 2018. DOI:10.1177/1687814018808697.

[18] J. Yao, F. Xing, Y. Fu, et al. Failure analysis of torsional buckling of all-terrain crane telescopic boom section. Engineering Failure Analysis 73:72 - 84, 2017. DOI:10.1016/j.engfailanal.2016.12.006

[19] R. Mijailovic. Modelling the dynamic behaviour of the truck-crane. Transport 26(4):410 - 417, 2011. DOI:10.3846/16484142.2011.642946.

[20] P. Jia, E. Li, Z. Liang, Y. Qiang. Dynamic stability of the aerial work platform based on ZMP. In Third International Conference on Intelligent Control and Information Processing, pp. 422 - 425. IEEE, Dalian, China, 2012. DOI:10.1109/icicip.2012.6391539 